\title{
Digitalization and Artificial Intelligence in Migration and Mobility: Transnational Implications of the COVID-19 Pandemic
}

\author{
Marie McAuliffe ${ }^{1}$, Jenna Blower ${ }^{2, *}$ and Ana Beduschi ${ }^{3}$ \\ 1 International Organization for Migration, The Australian National University, Canberra, ACT 0200, Australia; \\ marie.mcauliffe@anu.edu.au \\ 2 Department of Social Anthropology, York University, Toronto, ON M3J 1P3, Canada \\ 3 Law School, University of Exeter, Exeter EX4 4PY, UK; a.beduschi@exeter.ac.uk \\ * Correspondence: jenna.blower@hotmail.ca
}

Citation: McAuliffe, M.; Blower, J.; Beduschi, A. Digitalization and Artificial Intelligence in Migration and Mobility: Transnational Implications of the COVID-19 Pandemic. Societies 2021, 11, 135. https://doi.org/10.3390/soc11040135

Academic Editors: Sandro Serpa and Carlos Miguel Ferreira

Received: 22 September 2021

Accepted: 7 November 2021

Published: 10 November 2021

Publisher's Note: MDPI stays neutral with regard to jurisdictional claims in published maps and institutional affiliations.

Copyright: (c) 2021 by the authors. Licensee MDPI, Basel, Switzerland. This article is an open access article distributed under the terms and conditions of the Creative Commons Attribution (CC BY) license (https:/ / creativecommons.org/licenses/by/ $4.0 /)$.

\begin{abstract}
Digitalization and artificial intelligence (AI) technologies in migration and mobility have incrementally expanded over recent years. Iterative approaches to AI deployment experienced a surge during 2020 and into 2021, largely due to COVID-19 forcing greater reliance on advanced digital technology to monitor, inform and respond to the pandemic. This paper critically examines the implications of intensifying digitalization and AI for migration and mobility systems for a postCOVID transnational context. First, it situates digitalization and AI in migration by analyzing its uptake throughout the Migration Cycle. Second, the article evaluates the current challenges and, opportunities to migrants and migration systems brought about by deepening digitalization due to COVID-19, finding that while these expanding technologies can bolster human rights and support international development, potential gains can and are being eroded because of design, development and implementation aspects. Through a critical review of available literature on the subject, this paper argues that recent changes brought about by COVID-19 highlight that computational advances need to incorporate human rights throughout design and development stages, extending well beyond technical feasibility. This also extends beyond tech company references to inclusivity and transparency and requires analysis of systemic risks to migration and mobility regimes arising from advances in $\mathrm{AI}$ and related technologies.
\end{abstract}

Keywords: international migration; mobility; Migration Cycle; artificial intelligence; digitalization; digital divide; COVID-19; human rights

\section{Introduction}

In the current era of online connectivity, described by some as the Age of Algorithms [1], increasingly complex digital technologies including those related to artificial intelligence (AI) underpin more and more everyday activities performed by people all over the world. Substantial developments in computational power and data generation have resulted in people's daily lives being shaped through AI-related services and digital interfaces, such as the personalization of newsfeeds, online advertising tailored to browsing activity, interactive chatbot assistance and automated analytical updates. The range of "smart" products using AI technologies has also grown, now covering appliances, vehicles, houses and integrated voice assistants.

Routine activities in day-to-day lives around the world speak volumes of the recent emergence of modern-day digital transformations. Sending e-mails, transferring money to family back home, searching online for information and advice, posting comments on social media and lodging e-forms through online platforms have become routine even in the most geographically remote locations. This is especially the case for interactions related to international migration and mobility, which is an inherently transnational phenomenon 
that has been shaped by social networks over hundreds of years often involving personto-person links built up over generations [2,3]. Over recent years, however, our social and economic interactions have been increasingly mediated through digital systems and processes, placing much greater emphasis on digital technologies and reducing the need for personal interaction [4].

Alongside the impacts on individuals, the pressure on industry to digitalize has resulted in every sector (and, to a lesser degree, all organizations) needing to transform its systems, structures and processes toward data capture, storage, reporting and related analysis. As part of these digital transformations, we have seen the management of migration and mobility systems globally being affected by increased digitalization and improving AI capabilities. The use of these data-driven technologies is not new, with some countries having utilized AI in their migration management systems for more than two decades, including as a means to manage rising demand for visa and travel-related products and services [5]. AI is increasingly used throughout the Migration Cycle, for example, to facilitate pre-departure identity checks, support online visa applications, manage administrative decision-making, enable "smart" border processing, and produce data analytics on travelers' compliance with legal frameworks.

AI technologies can help people access up-to-date information in real-time, improve system efficiency and reduce service times for clients. However, AI poses a variety of issues for policymakers, practitioners and migrants, including concerns about technology-enabled surveillance of individuals, the potential for systemic bias in AI decision-making in the areas of migration and mobility, the increased interactions between public and private sectors and their competing interests, and the negative impact of AI technologies on the protection of human rights.

Data-driven AI technologies have also played a critical role in the fight against COVID-19, especially during the initial months of the pandemic. Many governments and businesses around the world quickly developed digital solutions to monitor public health, such as mobile phone applications for contact tracing to support self-isolation strategies aimed at minimizing transmission rates [6-8]. COVID-19, and the urgency related to immediate responses, acted to further intensify the pre-existing pressures on industry and States to 'digitalize or perish' $[9,10]$. It had become a matter of life and death, on a large scale, and closely linked to the movement of people across borders as well as within local communities.

This paper critically examines the implications of intensifying digitalization and AI for migration and mobility systems for a post-COVID transnational context. First, it situates digitalization and AI in migration by analyzing its uptake throughout the Migration Cycle. Second, the article evaluates the current challenges and opportunities to migrants and migration systems brought about by the deepening digitalization due to COVID-19, with reference to human rights and international development. This is important because of the widely recognized risks AI implementation poses to the adherence of human rights, most especially concerning identity and privacy [11,12]. In addition, the potential impacts of the "digital divide" extend beyond individuals and communities, taking in entire countries beset by global inequalities. Further leaps in the roll-out of super technologies in migration and mobility regimes, such as AI, risk further polarizing the potential for developing countries to also realize a global mobility dividend.

In writing this paper the researchers conducted a review of the available literature on this subject drawing from academic articles published in peer-reviewed journals, research reports, and other relevant national and international government documents on migration management, AI and COVID-19. Document analysis was used as the primary research method, drawing on the available literature to provide new insight into the implications of increasing digitalization and use of $\mathrm{AI}$ in migration and mobility systems for a post-COVID transnational context. 


\section{From Abstract Conceptualizations to Functional Realities: The AI and Migration Story So Far}

There is no universally agreed definition of AI. However, in a broad sense, it can be thought of as "the programming of computers to do tasks that would normally require human intelligence" [13]. With its roots in computer science of the 1950s, AI was initially conceived to convey the aspirational development of a computer that would deliver the high-level or cognitive capability of humans to reason and to think-otherwise referred to as "general AI" [14,15]. More than six decades later, high-level reasoning and thought remain elusive. Yet, AI technologies have developed over time to encapsulate different streams that utilize machine capabilities for such work as natural language processing, speech processing, machine learning, vision recognition, neural networks, and robotics [16,17]. AI-based systems can be purely software-based, acting in the virtual world (e.g., voice assistants, image analysis software, search engines, speech and face recognition systems) or AI can be embedded in hardware devices (e.g., advanced robots, autonomous cars, drones or Internet of Things applications) [14]. All of these AI technologies are relevant to migration and mobility systems, which operate in physical as well as virtual spaces.

The long-term trend toward computer-based migration and mobility systems involving the capture of vast amounts of data on travelers, movements, regulatory decisions and processes, has enabled the development and deployment of super technologies such as AI. AI technologies have increasingly been used in migration since the late 1990s, including in Australia, the United States, Japan and many European countries and by the European Union [18-20]. Increasing volumes of administrative processing - such as visa applications, airline check-ins, border point crossings-resulted in growing data repositories that were challenging for governments to utilize. This challenge, combined with increasing security risks associated with international travel particularly following the 9/11 terrorism attacks, saw many countries pursue AI in migration and mobility systems that also involved a distinct preference for optimizing security $[20,21]$. Early investments in machine learning and other analytical capabilities significantly enhanced States' abilities to monitor their borders and implement pre-entry detection systems, including by analyzing data on hundreds of millions of border crossings amounting to many gigabytes of "unstructured intelligence" [22]. It is also important to note that AI technologies rely on underlying data capture and digital capabilities in order to be applied. "Digitalization" of aspects of migration systems is, therefore, a necessary condition for the application of AI technologies. However, digitalization does not necessarily result in AI technologies being developed and implemented. Compared with digitalization, $\mathrm{AI}$ in migration and mobility is currently much more limited, although it has experienced a surge in focus over the last 12-18 months.

To situate the analysis of digitalization and AI in migration, we apply the analytical framework of the "Migration Cycle" $[23,24]$ to demonstrate its broader applicability that is much wider than the more obvious areas of border management and visa processing. The increase in digital capture means that AI has been used throughout the Migration Cycle at all stages: pre-departure, entry, stay and return (see Figure 1). 


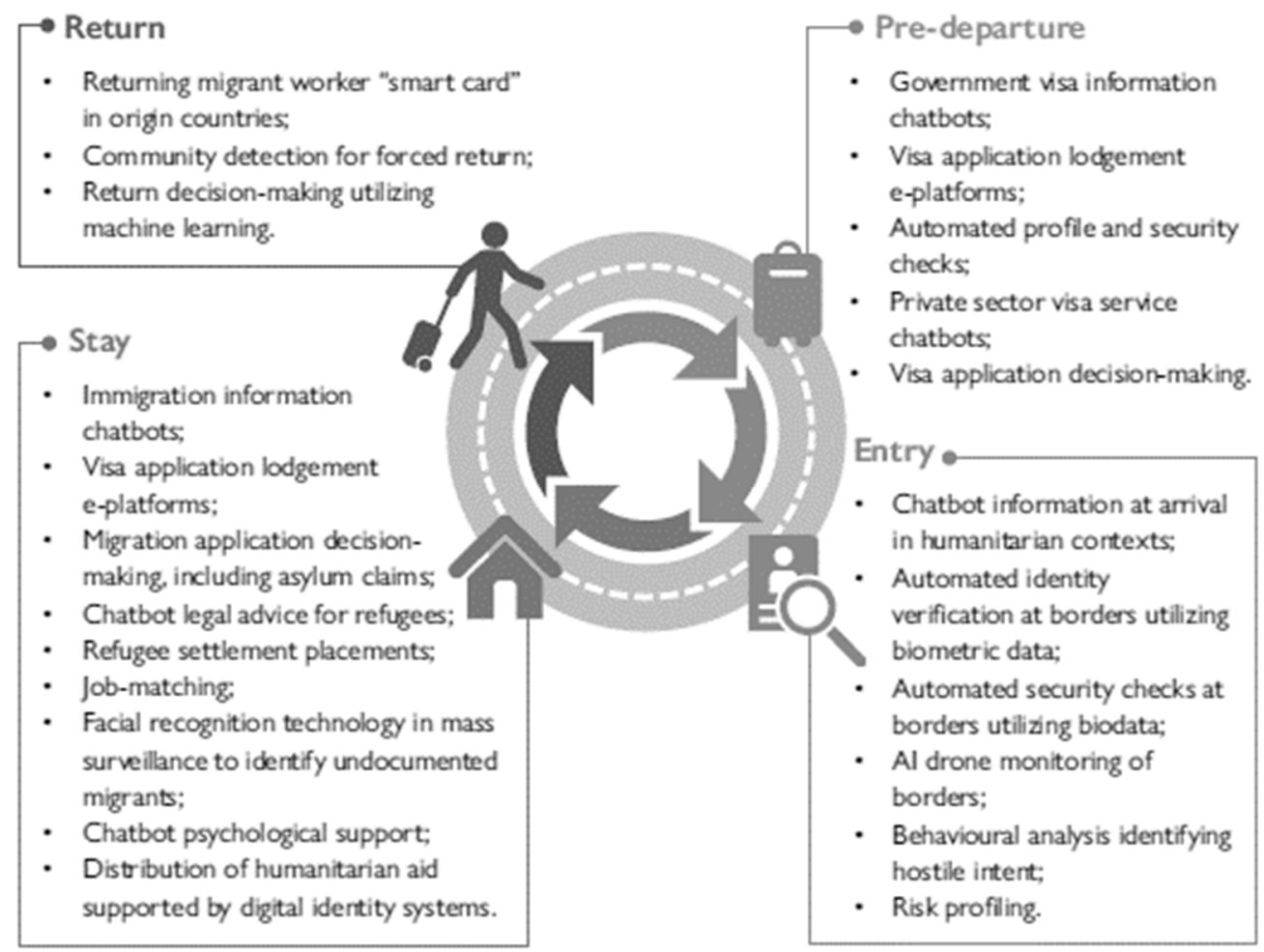

Figure 1. AI and the Migration Cycle.

As can be seen in Figure 1, the advancement of AI through the Migration Cycle has extended beyond its initial focus on pre-departure and entry. Similarly, the expansion has occurred alongside an increase in the variety of actors involved in the creation and management of such systems, posing concerns for the data management and privacy of highly sensitive information across various jurisdictions. These non-state actors span the public and private domains including civil society, large corporations and agencies such as airlines and 'platform companies' such as Facebook and Google [25-27]. Multinational technology corporations that operate transnationally are increasingly involved in the development of AI systems in migration, often for government clients, and their data collection and analytical capabilities extend beyond borders and national boundaries. However, an underlying profit motive means that much of the development and implementation globally is situated in high-income economies, resulting in profound asymmetry between countries in terms of the use of AI technologies in migration and mobility systems [5].

States with developed capabilities in AI technologies could thus be placed in a leading position at the forefront of the global efforts to manage migration. Consequently, States with less advanced technologies could be further isolated. Such a situation could create a new paradigm, an AI divide, whereby AI-capable States would set the agenda and priorities for international migration management. That is particularly relevant as States viewed as more authoritarian regimes may be placed on the same side of the AI divide with traditional western liberal democracies, due to the development in AI capabilities around the world. Such a scenario may have significant consequences for migration and mobility, as the AI divide could either reinforce or, conversely, depart from the north-south migration paradigm [5]. The drive to accelerate the digital transformation and increase AI capabilities in migration is also deeply influenced by the worldwide efforts to curb the COVID-19 pandemic, as discussed in the next section.

\section{Digital Technologies and AI throughout the Migration Cycle during COVID-19}

Digital technology and AI interventions have advanced and taken new forms as a result of COVID-19 management strategies to curb the spread of the virus such as contact tracing, quarantine measures, and crowd surveillance. Using the Migration Cycle as a 
framework, this section examines these evolving technologies and the ways in which migrants' journeys are impacted by digital advances during the COVID-19 pandemic (See Figure 2. COVID-19 Technological Interventions throughout the Migration Cycle).

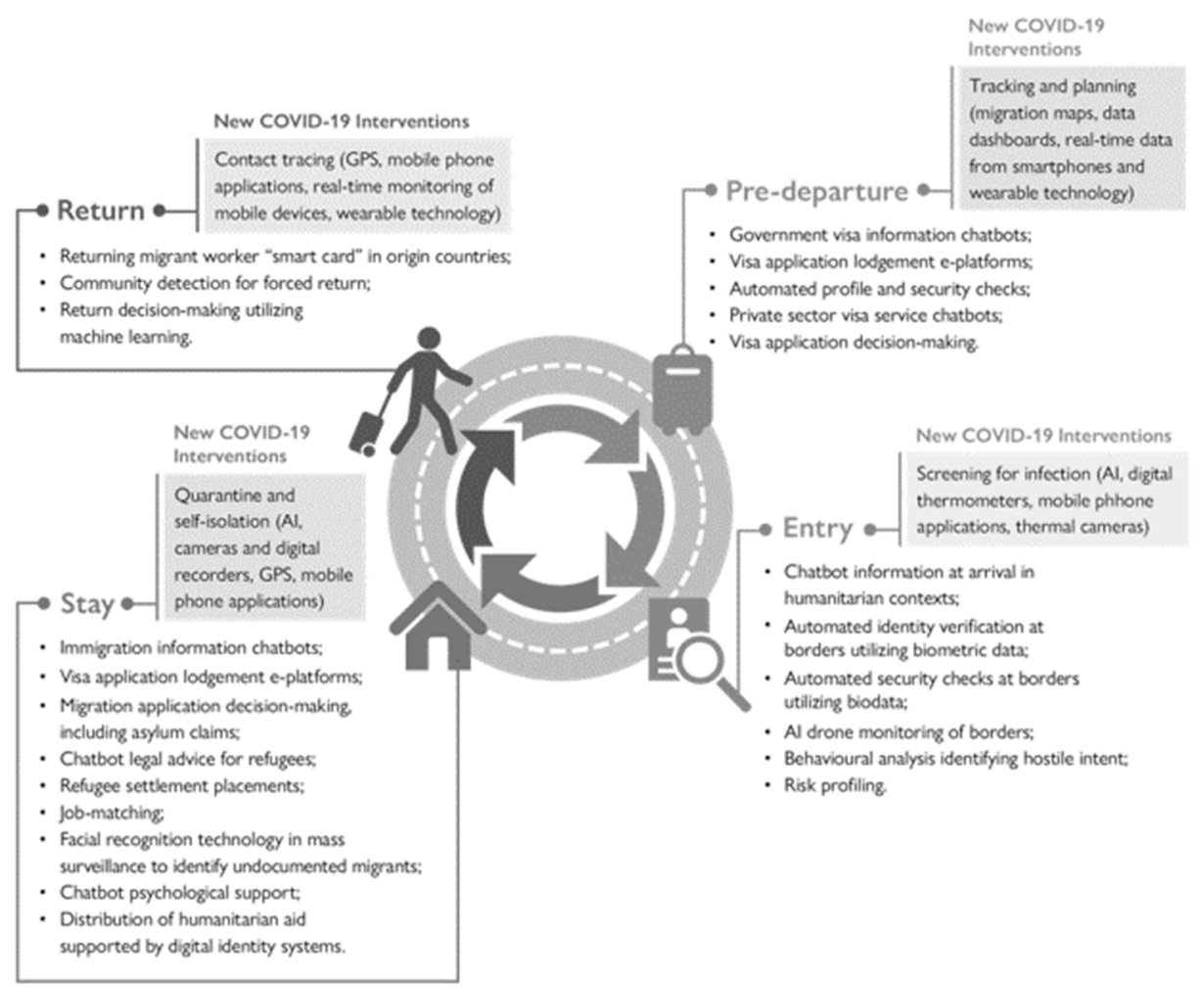

Figure 2. COVID-19 Technological Interventions throughout the Migration Cycle.

\subsection{Pre-Departure: The Role of Mobility Data}

From global data dashboards and neighbourhood maps to personal wearable technology, devices producing real-time data aimed to track and monitor the spread of the virus and subsequently the movement of people has become all the more significant during COVID-19. The data produced by AI, mobility monitoring platforms and wearable technology helps to inform COVID-19 impact strategies, including lockdown measures, border closures and other restrictions to movement. Big tech companies have released mobility data, for example, Google's 'community mobility reports' and Facebook's 'movement range trends' report. Both companies emphasize that the aggregated data is anonymous and based on users who opt in to share their location history, which is turned off by default $[28,29]$. Facebook (n.d.) describes how population density maps rely on data collected from users and are combined with satellite imagery from machine vision $\mathrm{AI}$ and census information. Such data sets are intended to inform public health officials and researchers how people are responding to COVID-19 interventions such as social distancing measures and lockdowns [30,31], however, limitations are revealed in assessing how accurately the data represents the examined population as there is no information on the number of 'users' accounted for in the Google and Facebook outputs or if any strategies are applied in the data analysis to account for demographic and/or other biases [32].

Mobility data are made available through mobile phones and also through wearable technology, defined as "communication enhancing devices worn on the body that are connected to an internet source", for example, smartwatches and fitness trackers [6] (p. 90243). These movement tracking devices are supported by Bluetooth, GPS, and GIS technologies, which raises serious privacy concerns. Notably, there are few guidelines and regulations about the use of this private data and what is entailed in information sharing [6]. Critical to 
the safety of individuals, private telecom companies maintain a database of these records and authorities can gain access to users' exact locations [27].

In the context of COVID-19, mobility data directly relates to the pre-departure stage of the Migration Cycle due to its influence on the prediction and modelling of population movement, tracking the spread of the virus, and subsequently implementing movement restrictions. The acceleration of technology and use of big data and AI due to COVID-19 has direct impacts on migrants in the immediate and the foreseeable future [26,33]. Big data, recognized for its ability to process high-volume information, from a variety of sources and at a high velocity, enables decision making and process automation [34]. Big data is currently being leveraged to monitor migrants approaching the border [33], with experiments taking place at EU borders, for example, to predict population movements and inform automated decision-making in immigration applications [26]. In keeping with this trend, the ways in which big data analytics are being used to monitor movement at border points will continue to intensify.

\subsection{Entry: Increased (Bio)Surveillance}

There is a range of technological interventions that migrants, and citizens alike, are subject to at border points upon entry. Drone technology, which relies on AI applications, for example, has become particularly significant in the context of COVID-19, due to its ability to survey and observe crowds, conduct thermal imaging to screen for those with a high body temperature, sanitize public spaces, and even carry essential medical supplies [6,35]. Unmanned aerial vehicles have become a large part of migration management technologies and are regularly used to monitor border sites [33]. The European Commission's ROBORDER project, is an example of how such technologies are advancing, as the project seeks to create a "fully-functional autonomous border surveillance system with unmanned mobile robots including aerial, water surface, underwater and ground vehicles" [36]. These technologies have far-reaching human rights implications due to the accumulation of private data and the lack of regulatory policies in place [26]. Additionally, there are security risks as drones are vulnerable to GPS-jamming and hacking for users to conduct criminal activity [6].

Integrated into drone technology and other surveillance devices is the capturing of biometrics, the collection of data through "physiological or behavioral traits such as voice recognition, fingerprints, retinal recognition or facial thermograms" [25]. Face scanners, for example, are equipped with AI-based multisensory technology and have been adopted in airports in efforts to identify individuals with symptoms of COVID-19 and limit exposure to frontline staff [6]. These camera technologies collect real-time data and often rely on AI machine learning to screen and diagnose individuals and produce research that supports virus modelling and risk prediction [6]. The collection of biometric data raises serious questions about how the data is stored, who owns it, who can access it, and how it will be protected $[25,26,37]$. The increase of surveillance technologies that utilize biometrics has given rise to "virtual" or "digital" borders which have great implications for migration [25,37]. For one, biometric identifiers as a prerequisite for travel is expanding, we see this especially in the context of COVID-19 with the requirements for proof of vaccination and COVID-19 test results [38]. While there is no consensus on COVID-19 health status certificates as a prerequisite for international travel [39], the inequitable vaccine access may act to reduce international mobility. Those unable to access vaccination programs in developing countries will face obstacles to international travel, further to the already significant visa restrictions [40]. In addition, vaccination registration and identity verification may also deter migrants in an irregular situation from being vaccinated, which may not only exclude them from access to COVID-19 certificates but also jeopardize broader public health goals [41]. 


\subsection{Stay: Quarantine, Testing, and Healthcare Provision}

Digital technologies have been incorporated into various COVID-19 management strategies including mandated quarantine and self-isolation. Techniques employed in this context have grave implications for migration and mobility systems. For example, in Taiwan, quarantined individuals were monitored through government-issued mobile phones and tracked by GPS. If individuals breached their quarantine by crossing a "digital fence", a message was sent to the individual and individuals were issued fines [42]. Similarly, many countries instructed individuals to download a mobile phone application to selfreport COVID-19 symptoms and self-isolate [43]. For migrants in particular, the collection of personal data for public health purposes, raises concerns for their privacy and safety. Immigrants have expressed concerns accessing COVID-19 related programs due to the fear of exposing their immigration status [44,45]. Examples of extracting personal data from mobile phones stem into migration and mobility management practices, as it is becoming common among authorities to use personal electronic devices as a verification tool, gaining access to call data, text messages, location history and more [26]. Advocates call for the establishment of firewalls between health and immigration authorities to encourage the uptake of COVID-19 technologies and protect the rights of migrants [45].

The digital transformation of healthcare provision has also uniquely informed mobility and migration systems and has implications for migrants themselves, especially when it comes to accessing healthcare services. The application of health-related technologies during the pandemic has been imperative to provide virtual care, track medication orders, and communicate health information from wearable technology to healthcare professionals $[35,43]$. For example, in the United States, Kinsa Health, a technology company that created smart thermometers that connect to a mobile application, generates daily maps illustrating potential hot spots across the United States. Such technology works to track the spread of the virus and inform public health safety measures, such as when to implement movement restrictions, for example, curfews and lockdowns [46]. Additionally, COVID-19 has given rise to a suite of virtual healthcare services and telehealth platforms. While some have been designed with migrants in mind, such as "Karim the Chatbot X2AI", a program created to deliver remote psychotherapy to Syrians in the Zaatari refugee camp [47,48], the streamlining of remote healthcare services raises concerns for migrants who may lack access to a stable computer and internet access, lack digital proficiency, and do not access available services due to privacy concerns [49]. The use of digital technologies within migrant communities prompts further reflection on the use of digital technologies during COVID-19 and how it exacerbates not only the "digital divide" with unequal access to technology and networks but also inequality with lasting implications for health and security.

\subsection{Return: Contact Tracing and the Digitalization of Visa Applications}

According to the World Health Organization (WHO) contact tracing involves the identification of individuals who have come in contact with an infected person(s), recording the details of those individuals, and getting tested for infection [50]. The exercise of contact tracing requires people to willingly have their personal details captured, often in a government-protected database, to help curb the spread of the virus [8]. From large-scale surveillance cameras to mobile phone applications and wearable technology, digital technologies have been adopted to aid the process of contact tracing. In South Korea, for example, a combination of data is pulled from "security camera footage, facial recognition technology, bank card records, and GPS data from vehicles and mobile phones" to produce real-time data on people's travel [43] (p. 436). Using a mobile phone application, individuals are then notified of COVID-19 cases nearby and instructed to visit a testing centre $[43,51]$. Singapore has also implemented a mobile phone application using Bluetooth signals that allow individuals to keep track of who they are in proximity to. When an individual is diagnosed with COVID-19, public health officials will access the data to identify individuals who were in contact with the infected person $[43,52]$. While both Singapore and South Korea have maintained record low COVID-19 mortality rates [43], 
for contact tracing to be effective, Oxford University researchers suggest that over half the population would need to adopt the technology [53]. Utilizing contact-tracing applications may be a challenge for migrants due to connectivity issues, and as a migrant advocacy organization reports, migrants often share devices or lack a mobile phone all together [53].

COVID-19 disrupted forced and voluntary return procedures, however, to adapt to various travel restrictions and office closures, many countries began to accept immigration applications by post and email, issuing documents digitally [54]. There are drawbacks to online systems including access to technology by applicants, data protection and quality control [54]. The digitalization of migration management regarding online applications and the issuing of visas existed prior to the pandemic. For example, Canada, the United States, and the EU have been investing in AI algorithms to automate decisions on visa applications [33]. The pandemic has heightened the need for digital services, and it is likely the integration and adoption of digital technologies will continue to accelerate.

\section{Implications for Migrants, Migration Trends and Migration Corridors}

As discussed in the previous sections, digitalization and AI are increasingly becoming a common feature of migration and mobility. The COVID-19 pandemic further accelerated the adoption of technology-driven solutions that directly impact migration and mobility systems. While technological innovation presents many opportunities, notably concerning migrants' access to information and services throughout the Migration Cycle, the potential over-reliance on these technologies also brings about significant challenges. Two key areas of interest can be highlighted in this regard, concerning the protection of migrants human rights, and the effects on long-term migration trends and the implications for migration corridors.

\subsection{Protection of Migrants' Human Rights}

While the challenges posed by the development of digital technologies and AI are not exclusive to migration, the power imbalance between migrants and public authorities may aggravate existing weaknesses in protecting their human rights. Two areas are of particular interest-the potential for algorithmic bias to exacerbate inequalities and lead to unlawful discrimination and the effects of increased surveillance on the protection of migrants' right to privacy.

First, research demonstrates that AI systems can reflect the biases of their human creators [55-57]. For instance, bias may arise from a lack of representation and diversity in datasets used to train AI algorithms [56]. For example, researchers found that due to a lack of diversity in the datasets used for training commercially available facial recognition algorithms, these were significantly less accurate when recognizing women's faces with darker skin types [58].

AI systems may also reflect structural and historical bias against minorities [57]. For instance, researchers demonstrated that AI systems operating sentiment analysis, a technique allowing text to be marked as having a positive or a negative meaning, showed significant race and gender bias [59].

While bias is not exclusively related to migration and mobility, the consequences for migrants' rights are significant. For example, if facial recognition technologies are used for identification and identity verification of migrants, individuals with darker skin types may be more exposed to inaccuracies and misidentification. If such mistakes are not corrected, misidentification may lead to exclusion from access to assistance and services throughout the Migration Cycle, and potentially, unlawful discrimination based on race [60].

Certainly, bias may go undetected in AI systems, particularly due to a lack of transparency and auditability of proprietary AI algorithms-the so-called "black box" problem $[11,61]$. Yet, in areas where the evidence clearly indicates a high risk of bias, such as in facial recognition technologies, it is possible to argue that authorities ought to know about those risks. Suppose public authorities still deploy these AI systems for decision-making concerning migrants without addressing the issue of bias. In that case, they may be ex- 
posing migrants to unlawful discrimination on the grounds of race, gender, or any other protected characteristic (as per Article 7 of the Universal Declaration of Human Rights, Article 26 of the International Covenant on Civil and Political Rights, Article 14 of the European Convention on Human Rights, Article 24 of the American Convention on Human Rights, and Article 3 of the African Charter on Human and Peoples' Rights) [62,63].

Second, as discussed in the previous sections, digital technologies, including AI, contribute to the technologization of migration and mobility. Consequently, that can lead to an intensification of migrant surveillance practices. In addition, the urgency surrounding the COVID-19 pandemic has also led to public authorities increasingly experimenting with digital technologies without due public scrutiny — with migrants and other marginalized communities often more severely impacted [26,64].

Certainly, there are practical advantages in using digital technologies and AI in migration, for example, streamlining repetitive tasks requiring large amounts of data processing. However, technology-enabled surveillance of migrants, notably at borders, can disproportionately interfere with their right to privacy [65].

Under International Human Rights Law, everyone has the right to respect for their private life (as per Article 12 of the Universal Declaration of Human Rights, Article 17 of the International Covenant on Civil and Political Rights, Article 8 of the European Convention on Human Rights, Article 11 of the American Convention on Human Rights). This right is also protected in the digital space, as "the same rights that people have offline must also be protected online, including the right to privacy" [66] (para. 3).

The right to respect one's private life encompasses telecommunications and electronic data [67-72]. The protection of this right extends to non-nationals insofar as they fall within the jurisdiction of a State party to an international treaty recognizing this right [73].

Yet, the right to privacy is not absolute. Public authorities may impose restrictions insofar as these are not arbitrary. For instance, under Article 8, paragraph 2 of the European Convention on Human Rights, restrictions must be adopted in accordance with the law, follow a legitimate interest (such as national security, public safety, the prevention of disorder or crime, or the protection of the rights and freedoms of others) and satisfy the tests of necessity and proportionality. In the EU, the General Data Protection Regulation (GDPR) also recognize restrictions on data protection, including in the interests of national security and public security (Article 23 paragraph 1 of the GDPR).

Accordingly, public authorities should strike a fair balance between protecting migrants' right to privacy and increasing their digital and AI capabilities to support migration management and border security and control. In addition to the impact on migrants' rights, digitalization and AI also have important effects on migration trends, as discussed below.

\subsection{Effects on Long-Term Migration Trends and Migration Corridors}

Digital technologies and AI are likely to impact international migration patterns over time. If progressively more occupations become automated or replaced by computers, the future of work and that of trends in work-related migration may be affected.

Research demonstrates that automation, $\mathrm{AI}$ and advanced robotics risk rendering the recourse to many migrant workers obsolete in key destination economies [74-77]. Changes in the nature of work within existing jobs, also motivated by the COVID-19 pandemic, may force workers to be increasingly flexible, adaptable and focused on managerial and social skills while machines and computers may take over a growing share of repetitive and routine tasks. For instance, COVID-19 has accelerated the search for scalable automated crop harvesting solutions utilising robotics in order to reduce the reliance on temporary migrant workers [74].

Accordingly, less well-educated and low-skilled workers, who tend to undertake more routine tasks, may be particularly affected by automation [75,76]. For example, in a report focusing on Bahrain, Egypt, Kuwait, Oman, Saudi Arabia and the UAE, researchers found that the automation of routine work is particularly relevant to low-skilled migrant workers 
in these countries. For instance, in the UAE, over $93 \%$ of automation potential may affect jobs currently held by migrant workers [77].

Yet, research suggests that changes in work patterns may also affect professional "white-collar" jobs and consequently, migration and mobility of skilled and high-skilled migrants [78]. For instance, the bestowing of citizenship to the Sofia robot in 2017 by Saudi Arabia may have signalled the country's willingness to "fast-track" technological solutions and to afford robots with status often unattainable by migrant workers [79].

\section{Conclusions}

Digitalization and AI technologies have been progressively utilized in migration and mobility. As analysed in this paper, the advancement of AI and digital technologies through the Migration Cycle has extended beyond its initial focus on pre-departure and entry. AI and digital technologies are also a feature of stay and return programs and initiatives. Examples include the digitalization of visa and asylum applications and processing, automated security checks at borders and AI-powered immigration information chatbots. Digital technologies and AI in migration and mobility are likely to continue expanding in the upcoming years.

The COVID-19 pandemic has exposed the need for better digital technologies to support the management strategies aimed at curbing the spread of the virus. These included digitalization regarding contact tracing, quarantine measures, and crowd surveillance. Such advances in digital technologies have also impacted migrants' journeys during the pandemic. For instance, mobility data has played an important role in pre-departure strategies as they were used to predict and model population movement, track the spread of the virus, and subsequently, for decision-making concerning movement restrictions. Similarly, the COVID-19 pandemic led to an increase in the utilization of drones relying on AI applications and unmanned aerial vehicles for population and border surveillance.

While technological innovation presents many opportunities, notably concerning migrants' access to information and services throughout the Migration Cycle, the potential over-reliance on these technologies also brings about significant challenges.

The protection of migrants' human rights can be particularly affected by the advances in digital technologies and AI, notably due to the inherent power imbalance between migrants and public authorities. For example, algorithmic bias may exacerbate existing inequalities and lead to unlawful discrimination, which can significantly affect migrants. Similarly, the intensification of migrant surveillance practices has considerable effects on the protection of migrants' right to privacy.

In addition, digital technologies and AI are likely to impact international migration patterns over time, affecting long-term migration trends and migration corridors. In particular, the potential for increased automation and $\mathrm{AI}$ in certain areas of work and occupations, also motivated by the COVID-19 pandemic, may disrupt migration and mobility and even render the recourse to many migrant workers obsolete in key destination economies.

Accordingly, human rights should be incorporated in the design and development of digital technologies to mitigate potential risks to migrants' human rights. Similarly, decision-makers deploying these technologies should consider the systemic risks to migration and mobility regimes arising from advances in $\mathrm{AI}$ and related technologies. That is even more crucial in light of the transnational implications of the COVID-19 pandemic for migration and mobility.

Author Contributions: Conceptualization; formal analysis; writing original draft preparation; writing review and editing, all the authors; supervision, M.M. All authors have read and agreed to the published version of the manuscript.

Funding: This research received no external funding.

Data Availability Statement: Statement excluded.

Acknowledgments: The authors are grateful to the organizers of the May 2021 World Migration and Displacement Symposium-Harvard Data Science Review, USA for IOM and USA for UNHCR—for 
the opportunity to present initial analysis that formed the basis of this paper. Please note that views expressed are the authors' and do not necessarily reflect those of IOM or its member states.

Conflicts of Interest: The authors declare no conflict of interest.

\section{References}

1. Abiteboul, S.; Dowek, G. The Age of Algorithms; Cambridge University Press: Cambridge, UK, 2020.

2. Boyd, M. Family and personal networks in international migration: Recent developments and new agendas. Int. Migr. Rev. 1989, 23, 638-670. [CrossRef]

3. Massey, D.S.; Alarcón, R.; Durand, J.; González, H. Return to Aztlan: The Social Process of International Migration from Western Mexico; University of California Press: Berkeley, CA, USA; Los Angeles, CA, USA, 1987.

4. Hirsh-Pasek, K.M.; Schlesinger, R.; Michnick, G.; Care, E. The New Humanism: Technology should enhance, not replace, human interactions. Brook. Inst. 2018. Available online: https:/ /www.brookings.edu/blog/education-plus-development/2018/06/11 /the-new-humanism-technology-should-enhance-not-replace-human-interactions/ (accessed on 20 September 2021).

5. Beduschi, A. International migration management in the age of artificial intelligence. Migr. Stud. 2020, 1-21. [CrossRef]

6. Chamola, V.; Hassija, V.; Gupta, V.; Guizani, M. A Comprehensive Review of the COVID-19 Pandemic and the Role of IoT, Drones, AI, Blockchain, and 5G in Managing its Impact. IEEE Access 2020, 8, 90225-90265. [CrossRef]

7. Dong, Y.; Yao, Y.D. IoT Platform for COVID-19 Prevention and Control: A Survey. IEEE Access 2021, 9, 49929-49941. [CrossRef]

8. Kariuki, P.; Ofusori, L.O.; Subramaniam, P.R.; Okpeku, M.; Goyayi, M.L. Challenges in contact tracing by mining mobile phone location data for COVID-19: Implications for public governance in South Africa. Interdiscip. J. Inf. Knowl. Manag. 2021, 16, 101-124. [CrossRef]

9. Blum, S. Behaviour Detection Technology: Screening on the Go. Transp. Secur. Int. 2020. Available online: https://www.tsi-mag. com/behaviour-detection-technology-screening-on-the-go/ (accessed on 20 September 2021).

10. Gurbuz, I.; Ozkan, G. Transform or Perish: Preparing the Business for a Postpandemic Future. IEEE Eng. Manag. Rev. 2020, 48, 139-145. [CrossRef]

11. Pizzi, M.; Romanoff, M.; Engelhardt, T. AI for humanitarian action: Human rights and ethics. Int. Rev. Red Cross 2020, 102, 145-180. Available online: https://international-review.icrc.org/sites/default/files/reviewspdf/2021-03/ai-humanitarianaction-human-rights-ethics-913.pdf (accessed on 20 September 2021). [CrossRef]

12. United Nations Secretary-General. Report of the Secretary-General Roadmap for Digital Cooperation. New York. June 2020. Available online: www.un.org/en/content/digital-cooperation-roadmap/ (accessed on 20 September 2021).

13. Mehr, H. Artificial Intelligence for Citizen Services and Government. Harv. Kennedy Sch. 2017. Available online: https://ash. harvard.edu/files/ash/files/artificial_intelligence_for_citizen_services.pdf (accessed on 20 September 2021).

14. Jordan, M.I. Artificial Intelligence-The Revolution Hasn't Happened Yet. HDSR 2019. Available online: https://hdsr.mitpress. mit.edu/pub/wot7mkc1/release/9 (accessed on 20 September 2021).

15. Tegmark, M. Benefits and Risks of Artificial Intelligence. Future of Life Institute. 2016. Available online: https://futureoflife.org/ background/benefits-risks-of-artificial-intelligence/ (accessed on 20 September 2021).

16. McLaughlin, R.; Quan, T. On the Edge of Tomorrow-Canada's AI Augmented Workforce; Information and Communications Technology Council: Ottawa, ON, Canada, 2019. Available online: https://www.ictc-ctic.ca/wp-content/uploads/2020/02/canadas-aiworkforce-FINAL-ENG-2.24.20.pdf (accessed on 20 September 2021).

17. Angelov, P.P.; Soares, E.A. Towards explainable deep neural networks. Neural Netw. 2020, 130, 185-194. [CrossRef] [PubMed]

18. Australian National Audit Office (ANAO). DIAC's Management of the Introduction of Biometric Technologies; Department of Immigration and Citizenship: Canberra, Australia, 2008.

19. Frontex. Artificial Intelligence-Based Capabilities for the European Border and Coast Guard Final Report; Frontex, European Commission: Brussels, Belgium, 2021. Available online: https://frontex.europa.eu/assets/Publications/Research/Frontex_AI_research_ study_2020_final_report.pdf (accessed on 20 September 2021).

20. Rizvi, A. Designing and delivering visas. People Place 2004, 12, 45-52.

21. Faist, T. The Migration-Security Nexus: International Migration and Security Before and After 9/11; Willy Brandt Series of Working Papers in International Migration and Ethnic Relations; Malmo University: Malmö, Sweden, 2004.

22. Tay, L. Immigration targets 'problem travellers' with analytics. IT News, 5 November 2012. Available online: www.itnews.com. au/news/immigration-targets-problem-travellerswith-analytics-321562 (accessed on 20 September 2021).

23. Gmelch, G. Return Migration. Annu. Rev. Anthropol. 1980, 9, 135-159. [CrossRef] [PubMed]

24. McAuliffe, M.; Koser, K. A Long Way to Go. Irregular Migration Patterns, Processes, Drivers and Decision-Making; ANU Press: Canberra, Australia, 2017.

25. Bither, J.; Ziebarth, A. AI, Digital Identities, Biometrics, Blockchain: A Primer on the Use of Technology in Migration Management. Ger. Marshall Fund United States 2020. Available online: www.gmfus.org/publications/aidigital-identities-biometrics-blockchainprimer-use-technology-migration-management (accessed on 20 September 2021).

26. Molnar, P. Technological Testing Grounds: Migration Management Experiments from the Ground Up. EDRi Refug. Law Lab. 2020. Available online: https:/ / edri.org/wp-content/uploads/2020/11/Technological-Testing-Grounds.pdf (accessed on 20 September 2021). 
27. Puddephatt, A. Letting the Sun Shine in: Transparency and Accountability in the Digital Age; UNESCO: Paris, France, 2021. Available online: https:/ /ifap.ru/pr/2021/n210510c.pdf (accessed on 20 September 2021).

28. Herdagdelen, A.D.; State, B.; Mohassel, P.; Pompe, A. Protecting privacy in Facebook mobility data during the COVID-19 response. Facebook Res. 2020. Available online: https:/ / research.fb.com/blog/2020/06/protecting-privacy-in-facebook-mobilitydata-during-the-covid-19-response/ (accessed on 20 September 2021).

29. Google, Mobility Report CSV Documentation, COVID-19 Community Mobility Reports, 2020. Available online: https:/ www. google.com/covid19/mobility/data_documentation.html?hl=en (accessed on 20 September 2021).

30. Facebook, COVID-19 Interactive Map \& Dashboard, 2020. Available online: https:/ / dataforgood.facebook.com/covid-survey/ survey-and-map-data (accessed on 20 September 2021).

31. Facebook, Methodology: High Resolution Population Density Maps + Demographic Estimates, n.d. Available online: https: / / dataforgood.fb.com/docs/methodology-high-resolution-population-density-maps-demographic-estimates / (accessed on 20 September 2021).

32. Toh, A. Big Data Could Undermine the COVID-19 Response: Blind Spots in Location-Tracking Data Can Threaten Both Public Health and Human Rights. WIRED. 2020. Available online: https:/ / www.wired.com/story/big-data-could-undermine-thecovid-19-response/ (accessed on 20 September 2021).

33. Korkmaz, E.E. Refugees Are at Risk from Dystopian 'Smart Border' Technology, The Conversation, 2020. Available online: https:/ / theconversation.com/refugees-are-at-risk-from-dystopian-smart-border-technology-145500 (accessed on 20 September 2021).

34. Leclerc, B.; Cale, J. Big Data; Routledge: Milton Park, UK, 2020.

35. Chukwudi Okara, B.; Al-Turjman, F. Smart Technologies for COVID-19: The Strategic Approaches in Combating the Virus. Artif. Intell. Mach. Learn. 2021, 924, 1-23.

36. ROBORDER. Available online: https:/ / roborder.eu/ (accessed on 25 August 2021).

37. Nedelcu, M.; Sovsüren, I. Precarious migrants, migration regimes and digital technologies: The empowerment-control nexus. J. Ethn. Migr. Stud. 2020, 1-18. [CrossRef]

38. Beduschi, A. COVID-19 Health Status Certificates: Policy Recommendations on Data Privacy and Human Rights; University of Exeter: Exeter, UK, 2021.

39. World Committee on Tourism Ethics. Recommendation on COVID-19 Certificates for International Travel; UN World Tourism Organization: Madrid, Spain, 2021.

40. McAuliffe, M.; Kitimbo, A.; Goossens, A.M.; Ullah, A.A. Understanding migration journeys from migrants' perspectives. In World Migration Report 2018; McAuliffe, M., Ruhs, M., Eds.; IOM: Geneva, Switzerland, 2017.

41. UN Committee on Migrant Workers. Joint Guidance Note on Equitable Access to COVID-19 Vaccines for All Migrants; United Nations: Geneva, Switzerland, 2021.

42. Wang, J.; Ng, C.Y.; Brook, R.H. Response to COVID-19 in Taiwan: Big data analytics, new technology, and proactive testing. JAMA 2020, 323, 1341-1342. [CrossRef] [PubMed]

43. Whitelaw, S.; Mamas, M.A.; Topol, E.; Spall, H.G.C.V. Applications of Digital Technology in COVID-19 Pandemic Planning and Response. Lancet Digit. Health 2020. Available online: https://www.thelancet.com/journals/landig/article/PIIS2589-7500(20)3 0142-4/fulltext (accessed on 20 September 2021).

44. Galletly, C.L.; Lechuga, J.; Dickson-Gomez, J.B.; Glasman, L.R.; McAuliffe, T.L.; Espinoza-Madrigal, I. Assessment of COVID-19 Related Immigration Concerns Among Latinx Immigrants in the US. JAMA Netw. 2021, 4, e2117049. [CrossRef] [PubMed]

45. Global Detention Project. The Impact of COVID-19 on the Human Rights of Migrants. 2021. Available online: https: //www.globaldetentionproject.org/submission-to-the-un-special-rapporteur-on-the-human-rights-of-migrants-the-impactof-covid-19-on-the-human-rights-of-migrants (accessed on 20 September 2021).

46. Kinsa Inc. Available online: https:/ / kinsahealth.com/ (accessed on 25 August 2021).

47. Solon, O. Karim the AI delivers psychological support to Syrian refugees. Guardian 2016, 22. Available online: https://www. theguardian.com/technology/2016/mar/22/karim-the-ai-delivers-psychological-support-to-syrian-refugees (accessed on 20 September 2021).

48. Sengupta, Y. The Role of Chatbots in Mental Healthcare. DZone, 26 March 2019. Available online: https:/ /dzone.com/articles/ the-role-of-chatbots-in-mental-healthcare (accessed on 13 September 2021).

49. Brickhill-Atkinson, M.; Hauck, F.R. Impact of COVID-19 on Resettled Refugees. Prim. Care Clin. Off. Pract. 2021. Available online: https:/ / doi.org/10.1016/j.pop.2020.10.001 (accessed on 20 September 2021). [CrossRef] [PubMed]

50. World Health Organization (WHO). Contact Tracing in the Context of COVID-19. 2021. Available online: https://www.who.int/ publications/i/item/contact-tracing-in-the-context-of-covid-19 (accessed on 20 September 2021).

51. Fisher, M.; Sang-Hun, C. How South Korea Flattened the Curve. The New York Times, 23 March 2020. Available online: https:/ / www.nytimes.com/2020/03/23/world/asia/coronavirus-south-korea-flatten-curve.html (accessed on 20 September 2021).

52. Dick, S. Singapore's coronavirus temperature scans and tracking leading the way. The New Daily, 19 March 2020. Available online: https:/ / thenewdaily.com.au/news/national/2020/03/19/singapore-coronavirus-temperature-scans/ (accessed on 20 September 2021). 
53. Toh, A.; Brown, D. How Digital Contact Tracing for COVID-19 Could Worsen Inequality. Hum. Rights Watch, 4 June 2020. Available online: https://www.hrw.org/news/2020/06/04/how-digital-contact-tracing-covid-19-could-worsen-inequality (accessed on 20 September 2021).

54. European Migration Network and OECD. The Impact of COVID-19 in the Migration Area in EU and OECD countries. OECD 2021. Available online: https://www.oecd.org/migration/mig/00-eu-emn-covid19-umbrella-inform-en.pdf (accessed on 20 September 2021).

55. Friedman, B.; Nissenbaum, H. Bias in computer systems. ACM Trans. Inf. Syst. 1996, 14, 330-347. [CrossRef]

56. Zou, J.; Schiebinger, L. AI can be sexist and racist-It's time to make it fair. Nature 2018, 324-326. Available online: https: //www.nature.com/articles/d41586-018-05707-8 (accessed on 20 September 2021).

57. Suresh, H.; Guttag, J.V. A Framework for Understanding Unintended Consequences of Machine Learning. 2020. Available online: https: / / arxiv.org/pdf/1901.10002.pdf (accessed on 20 September 2021).

58. Buolamwini, J.; Gebru, T. Gender shades: Intersectional accuracy disparities in commercial gender classification. In Proceedings of the Conference on Fairness, Accountability and Transparency, New York, NY, USA, 29-31 January 2019.

59. Caliskan, A.; Bryson, J.J.; Narayanan, A. Semantics derived automatically from language corpora contain human-like biases. Science 2017, 356, 183-186. [CrossRef] [PubMed]

60. Israel, T. Facial recognition is transforming our borders and we are not prepared. Policy Options, 9 November 2020. Available online: https:/ / policyoptions.irpp.org/magazines/november-2020/facial-recognition-is-transforming-our-borders-and-weare-not-prepared/ (accessed on 20 September 2021).

61. Pasquale, F. The Black Box Society: The Secret Algorithms That Control Money and Information; Harvard University Press: Cambridge, UK, 2016.

62. UN General Assembly. Report of the Special Rapporteur Tendayi Achiume on Contemporary Forms of Racism, Racial Discrimination, Xenophobia and Related Intolerance; UN Doc A/75/590; United Nations: New York, NY, USA, 2020.

63. Sharkey, N. The impact of gender and race bias in AI. Humanit. Law Policy 2018. Available online: https://blogs.icrc.org/lawand-policy/2018/08/28/impact-gender-race-bias-ai/ (accessed on 20 September 2021).

64. Madianou, M. A Second-Order Disaster? Digital Technologies During the COVID-19 Pandemic. Soc. Media Soc. 2020, 6, 20563051209481681-5. [CrossRef] [PubMed]

65. Human Rights Council. Impact of the Use of Private Military and Security Services in Immigration and Border Management on the Protection of the Rights of All Migrants; Un Doc A/HRC/45/9; United Nations: Geneva, Switzerland, 2020.

66. UN General Assembly. Resolution 68/167. The Right to Privacy in the Digital Age; UNGA: New York, NY, USA, 2014.

67. Uzun v. Germany; ECHR 2010-VI; ECHR: Strasbourg, France, 2010.

68. S. and Marper v. UK ECHR 2008-V; ECHR: Strasbourg, France, UK, 2008.

69. Big Brother Watch and Others v UK; ECHR: Strasbourg, France, 2018.

70. Big Brother Watch and Others v UK; ECHR: Strasbourg, France, 2021.

71. Tristan Donoso v. Panama. Inter-American Court of Human Rights, Serie C No. 193, 27 January 2009. Available online: https:/ / globalfreedomofexpression.columbia.edu/cases/tristan-donoso-v-panama/ (accessed on 20 September 2021).

72. Escher v. Brazil. Inter-American Court of Human Rights, Serie C No. 200, 6 July 2009. Available online: https:// policehumanrightsresources.org/escher-et-al-v-brazil-series-c-no-200 (accessed on 20 September 2021).

73. UN General Assembly. Resolution 40/144. Declaration on the Human Rights of Individuals Who Are not Nationals of the Country in Which They Live; UNGA: New York, NY, USA, 1985.

74. Mitaritonna, C.; Ragot, L. After COVID-19, Will Seasonal Migrant Agricultural Workers in Europe Be Replaced by Robots? CEPII Policy Brief 2020. Available online: http:/ / www.cepii.fr/PDF_PUB/pb/2020/pb2020-33.pdf (accessed on 20 September 2021).

75. Ernst, E.; Merola, R.; Samaan, D. The Economics of Artificial Intelligence: Implications for the Future of Work. International Labour Organization; International Labour Organization: Geneva, Switzerland, 2018. [CrossRef]

76. Hertog, S. The future of migrant work in the GCC: Literature review and a research and policy agenda. In Proceedings of the Fifth Abu Dhabi Dialogue Ministerial Consultation, Dubai, United Arab Emirates, 16-17 October 2019. Available online: http:/ / eprints.lse.ac.uk/102382/1/Hertog_future_of_migrant_work_in_GCC_published.pdf (accessed on 20 September 2021).

77. Aus Dem Moore, J.P.; Chandran, V.; Schubert, J. The Future of Jobs in the Middle East. World Gov. Summit McKinsey Co. 2018. Available online: https://www.mckinsey.com/ \{\}/media/mckinsey/featured $\% 20$ insights $/$ middle $\% 20$ east $\% 20$ and $\% 20$ africa/are $\% 20$ middle $\% 20$ east $\% 20$ workers $\% 20$ ready $\% 20$ for $\% 20$ the $\% 20$ impact $\% 20$ of $\% 20$ automation/the-future-of-jobs-in-themiddle-east.ashx (accessed on 20 September 2021).

78. Hanke, P. Artificial Intelligence and Big Data-An Uncharted Territory for Migration Studies? Natl. Cent. Competence Res. 2017. Available online: https://nccr-onthemove.ch/blog/artificial-intelligence-and-big-data-an-uncharted-territory-for-migrationstudies / (accessed on 20 September 2021).

79. McAuliffe, M. The Link between Migration and Technology Is Not What You Think, Agenda; World Economic Forum: Geneva, Switzerland, 2018. Available online: https:/ / www.weforum.org/agenda/2018/12/social-media-is-casting-a-dark-shadow-overmigration/ (accessed on 20 September 2021). 